\title{
MODEL PEMILIHAN PROSES UNTUK MEMINIMALKAN BIAYA MANUFAKTUR, KERUGIAN KUALITAS, DAN KETERLAMBATAN PENGIRIMAN
}

\author{
ANI FATMAWATI ${ }^{1}$, CUCUK NUR ROSYIDI ${ }^{2}$, DAN WAKHID AHMAD JAUHARI ${ }^{3}$ \\ Jurusan Teknik Industri, Fakultas Teknik, Universitas Sebelas Maret
}

Laman: fatmawati032@gmail.com,cucuk@uns.ac.id,wakhidjauhari@uns.ac.id

\begin{abstract}
ABSTRAK
Strategi kompetitif yang dapat diterapkan oleh perusahaan meliputi tiga aspek, yaitu kualitas, biaya, dan waktu pengiriman. Namun, kenyataannya sulit untuk menghasilkan produk yang berkualitas tinggi dengan biaya manufaktur yang rendah serta waktu pengiriman yang tepat waktu. Oleh karena itu, perlu adanya pemilihan proses yang mengintegrasikan ketiga aspek tersebut agar dapat memenuhi kebutuhan konsumen. Penelitian ini membahas tentang model optimisasi pemilihan proses untuk meminimumkan biaya manufaktur, biaya kerugian kualitas, dan biaya keterlambatan pengiriman dengan mempertimbangkan spesifikasi komponen, waktu pengiriman, kapasitas produksi, dan pesanan konsumen. Contoh numerik diberikan untuk menunjukkan aplikasi model menggunakan produk rakitan yang terdiri dari tiga komponen penyusun. Terdapat tiga mesin yang dapat digunakan untuk memproduksi komponen. Setiap mesin mempunyai karakteristik yang berbeda dalam hal biaya manufaktur, toleransi, dan waktu proses. Total biaya yang dihasilkan untuk memproduksi 100 unit produk rakitan sebesar Rp5.390.970,00.
\end{abstract}

Kata kunci: Pemilihan proses, biaya manufaktur, kerugian kualitas, delivery time.

\begin{abstract}
There are three aspects of competitive strategy that can be applied by manufacturing companies: quality, cost, and delivery time. Actually, it is hard to produce high quality poducts in low manufacturing cost and on time delivery. Hence, a process selection is needed to integrated the three aspects above in order to meet a customer requirement. This research develops a process selection model to minimize manufacturing cost, quality loss cost, and lateness cost considering component spesification, delivery time, production capacity, and customer order. A numerical example is given to show the application of the model using an assembly product that consists of three components. Three machines are used to produce all of the components. Each machine has different characteristic in manufacturing cost, tolerances, and processing time. Total cost that used to produce 100 unit assembly product is Rp5.390.970,00.
\end{abstract}

Key words: Process selection, manufacturing cost, quality loss, delivery time.

\section{PENDAHULUAN}

Kompetisi yang semakin ketat saat ini membuat perusahaan berusaha untuk lebih unggul dibanding perusahaan lainnya. Biaya produksi bukan merupakan satu-satunya aspek yang dapat membuat sebuah perusahaan lebih unggul dibanding perusahaan lainnya. Menurut Irianto dan Rachmat (2008) ada beberapa aspek yang menjadi dasar strategi kompetitif perusahaan manufaktur untuk memenangkan kompetisi global yang dinamis yaitu biaya, kualitas, dan penyerahan order yang tepat waktu. Kualitas produk dapat dipengaruhi oleh kualitas bahan baku, kualitas komponen, dan kualitas proses produksi produk tersebut (Teeravaraprug, 2008). Kualitas proses produksi akan sangat dipengaruhi oleh mesin yang digunakan. Mesin yang memiliki tingkat presisi tinggi dapat menghasilkan toleransi yang lebih ketat sehingga akan menghasilkan produk dengan kualitas yang lebih tinggi. Perlu adanya pemilihan alternatif proses untuk menentukan proses yang akan digunakan. Namun, pemilihan ini semakin kompleks karena proses manufaktur dengan karakteristik biaya dan toleransi berbeda dari proses ke proses dan mesin ke mesin (Sivakumar dkk., 2011).

Spesifikasi toleransi sebuah komponen mempunyai dampak yang signifikan terhadap biaya manufaktur. Level kualitas yang semakin meningkat akan berpengaruh terhadap peningkatan biaya manufaktur dan memperpanjang lead time (Mustajib dan Irianto, 2010). Meskipun demikian, semakin ketat toleransi sebuah komponen atau produk akan menghasilkan komponen atau produk dengan kualitas 
yang lebih tinggi sehingga dapat memenuhi harapan konsumen. Usaha untuk menyeimbangkan biaya kerugian akibat variabilitas performansi komponen atau produk yang diterima konsumen dan biaya untuk mencapai performansi komponen atau produk yang dikeluarkan oleh perusahaan dapat diukur dengan menggunakan fungsi kerugian kualitas Taguchi (Mustajib dan Irianto, 2010). Fungsi kerugian kualitas Taguchi mengukur kerugian kualitas yang diterima konsumen karena penyimpangan nilai mean dari targetnya dan variasi produk rakitan. Pada sisi lain, spesifikasi toleransi antara lain berpengaruh terhadap pemilihan mesin, biaya setup, dan jumlah scrap dan rework (Kumar dkk., 2009).

Waktu pengiriman dapat dipengaruhi oleh upaya perusahaan untuk memenuhi kualitas komponen atau produk sehingga upaya tersebut dapat menambah lead time yang akhirnya dapat menyebabkan keterlambatan pengiriman (Mustajib, 2010). Apabila kualitas komponen semakin bagus, maka waktu proses yang digunakan untuk memproduksi komponen akan semakin lama sehingga dapat menyebabkan keterlambatan. Perusahaan dapat mengalami beberapa kerugian yang disebabkan oleh keterlambatan pengiriman. Salah satu kerugian yang ditimbulkan meliputi menurunnya reputasi perusahaan di kalangan konsumen yang dapat menyebabkan menurunnya re-purchasing hingga kehilangan penjualan. Kedua hal tersebut dapat menyebabkan penurunan pendapatan perusahaan. Apabila perusahaan tidak dapat mengirim komponen atau produk tepat waktu maka perusahaan akan dikenakan biaya keterlambatan.

Model optimasi dengan kriteria biaya pembelian dan biaya kerugian kualitas menggunakan fungsi kerugian Taguchi dikembangkan oleh Feng dkk. (2001). Irianto dkk. (2004) telah mengembangkan model pemilihan proses untuk meminimumkan biaya manufaktur dan kerugian kualitas dengan mempertimbangkan delivery time. Namun, dalam penelitian tersebut belum dipertimbangkan kapasitas produksi mesin dan permintaan konsumen. Irianto dan Rahmat (2008) mengembangkan model pemilihan proses dengan mempertimbangkan appraisal cost. Dalam penelitian ini digunakan batasan waktu proses namun belum dipertimbangkan adanya keterlambatan. Kumar dkk. (2009) mengembangkan pemilihan proses dengan alokasi toleransi menggunakan Lagrange Multiplier untuk meminimumkan biaya manufaktur. Hambali dkk. (2009) menyelesaikan pemilihan proses dengan metode kualitatif, Analytical Hierarchy Process (AHP) dengan menggunakan pembobotan terhadap faktor-faktor yang berpengaruh pada pemilihan proses. Faktor-faktor tersebut adalah rancangan geometri, karakteristik produksi, material, biaya, dan kemudahan dalam perawatan. Mustajib (2010) menjelaskan model pemilihan proses untuk banyak pabrik dengan fungsi tujuan meminimumkan total biaya. Total biaya dalam penelitian tersebut terdiri atas biaya manufaktur, biaya kerugian kualitas, dan biaya operasional untuk kolaborasi banyak pabrik.

Penelitian ini mengembangkan model pemilihan proses yang bertujuan untuk meminimalkan biaya manufaktur, kerugian kualitas, dan keterlambatan. Biaya keterlambatan juga diperhitungkan karena pada kenyataannya keterlambatan pengiriman dapat menyebabkan kerugian bagi perusahaan. Kerugian tersebut dapat berupa denda atau menurunnya re-purchasing yang berakibat pada menurunnya pendapatan perusahaan.

\section{METODE}

Penelitian dimulai dengan mengidentifikasi masalah. Proses ini meliputi studi literatur, perumusan masalah kemudian menetapkan tujuan. Langkah berikutnya yaitu tahap pengembangan model. Dalam proses ini digambarkan deskripsi sistim, penentuan fungsi tujuan dan kendala. Contoh numerik digunakan untuk menunjukkan aplikasi model yang telah dikembangkan. Proses terakhir adalah analisis terhadap model dan penarikan kesimpulan. Alur metodologi penelitian ditunjukkan dalam Gambar 1.

\section{Deskripsi Sistim}

Sebuah perusahaan perakitan memproduksi sendiri sejumlah $I$ komponen yang digunakan untuk merakit sebuah produk untuk memenuhi pesanan konsumen. Setiap komponen ke-i dapat diproduksi dengan proses manufaktur menggunakan mesin ke- $j$ pada tahapan ke- $k$. Perusahaan menggunakan mesin yang identik untuk memproduksi setiap komponen sehingga setiap mesin dapat melakukan proses produksi untuk semua komponen.

Setiap komponen ke- $i$ melalui satu kali tahap produksi pada mesin ke-j. Setiap komponen ke- $i$ yang diproses dengan mesin ke-j pada tahapan ke$k$ mempunyai karakteristik yang berbeda dalam hal toleransi, biaya manufaktur, dan waktu proses pembuatan komponen $\left(c_{i j k}, t_{i j k}, w_{i j k}\right)$.

Toleransi produk rakitan dari komponen ke- $i$ yang dihasilkan pada mesin ke-j tidak boleh melebihi batasan spesifikasi toleransi rakitan. Waktu proses untuk memproduksi semua komponen ke-i pada mesin ke-j pada tahapan ke- $k$ tidak boleh melebihi due date yang telah ditentukan oleh konsumen, jika terjadi keterlambatan maka perusahaan akan dikenai penalti berupa biaya keterlambatan. 


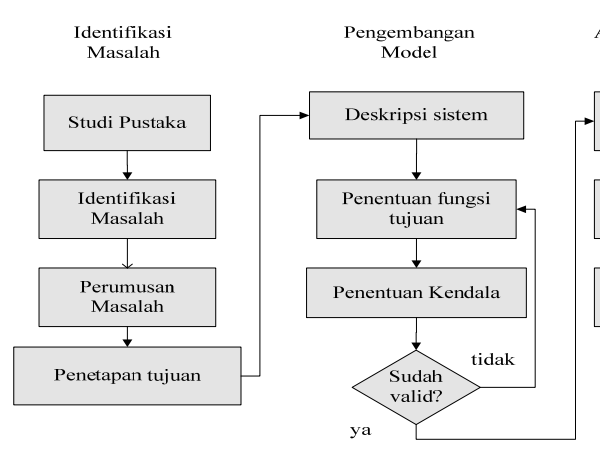

Gambar 1. Metodologi Penelitian

Setiap mesin ke-j tahapan ke- $k$ mempunyai kapasitas produksi tertentu, sehingga jumlah komponen yang diproduksi pada setiap mesin tidak dapat melebihi kapasitas produksi mesin tersebut. Apabila waktu penyelesaian semua pesanan tidak melebihi due date yang ditentukan maka tidak menimbulkan biaya keterlambatan, sedangkan pesanan yang dikirim setelah due date akan menimbulkan biaya keterlambatan. Deskripsi sistim ini ditunjukkan dalam Gambar 2.

\section{Pengembangan Model}

Model optimasi dalam makalah ini adalah memilih satu atau lebih mesin dari sejumlah alternatif mesin yang akan digunakan untuk memproduksi setiap komponen serta menentukan alokasi produksi pada setiap mesin, sehingga dihasilkan rancangan pemilihan mesin yang optimum. Variabel keputusan dalam model ini adalah mesin terpilih $\left(b_{i j k}\right)$ dan alokasi komponen $\left(x_{i j \mathrm{k}}\right)$. Pencarian solusi optimal menggunakan algoritma branch and bound.

\section{Notasi Model}

Notasi yang digunakan dalam pemilihan ini adalah sebagai berikut:

$i \quad$ : indeks yang menyatakan komponen

$j \quad$ : indeks yang menyatakan mesin

$k \quad$ : indeks yang menyatakan tahapan
TC : total biaya produksi

A : biaya kerugian kualitas

$D \quad$ : permintaan produk rakitan

$c_{i j k} \quad$ : biaya manufaktur komponen ke- $i$ yang diproses dengan mesin ke-j pada tahapan ke- $k$

$x_{i j k} \quad$ : jumlah komponen ke-i yang diproduksi pada mesin ke-j pada tahapan ke- $k$

$t_{i j k} \quad$ : toleransi komponen ke-i yang diproduksi pada mesin ke-j pada tahapan ke- $k$

$T_{R} \quad$ : toleransi rakitan

$\sigma_{K i j k}^{2} \quad$ : variansi komponen ke-i yang diproduksi pada mesin ke-j pada tahapan ke- $k$

$w_{i j k} \quad$ : waktu proses yang diperlukan oleh mesin ke-j pada tahapan ke- $k$ untuk memproses komponen ke-i

$w_{T} \quad$ : batas waktu pengiriman pesanan

$w_{\max }$ : total waktu mesin yang paling maksimum

$w_{k} \quad$ : waktu mesin terpanjang pada setiap tahapan ke- $k$

$k_{j k} \quad:$ kapasitas mesin ke-j pada tahapan ke- $k$

$b_{i j k} \quad$ : mesin ke-j yang terpilih yang dapat memproses komponen ke- $i$ pada tahapan ke- $k$. $b_{i j k}$ bernilai 1 jika dipilih dan bernilai 0 jika tidak terpilih.

$y \quad$ : jumlah keterlambatan

L : biaya keterlambatan

Formulasi Model

Setiap alternatif mesin ke-j tahapan ke- $k$ yang digunakan untuk memproduksi komponen ke-i menghasilkan variansi dimensi komponen sebesar $\sigma_{K i j k}^{2}$. Batasan spesifikasi toleransi menggunakan fungsi kerugian kualitas Taguchi, dimana total variansi proses setiap komponen ke-i yang diproduksi dengan mesin ke-j tahapan ke- $k$ harus lebih kecil atau sama dengan spesifikasi toleransi dimensi produk rakitan $\left(\sigma^{2}{ }_{R}\right)$. Biaya manufaktur yang dihasilkan untuk memproduksi komponen ke-i pada mesin ke-j adalah $c_{i j k}$. Sedangkan waktu proses untuk memproduksi setiap komponen pada satu mesin adalah $w_{i j k}$.

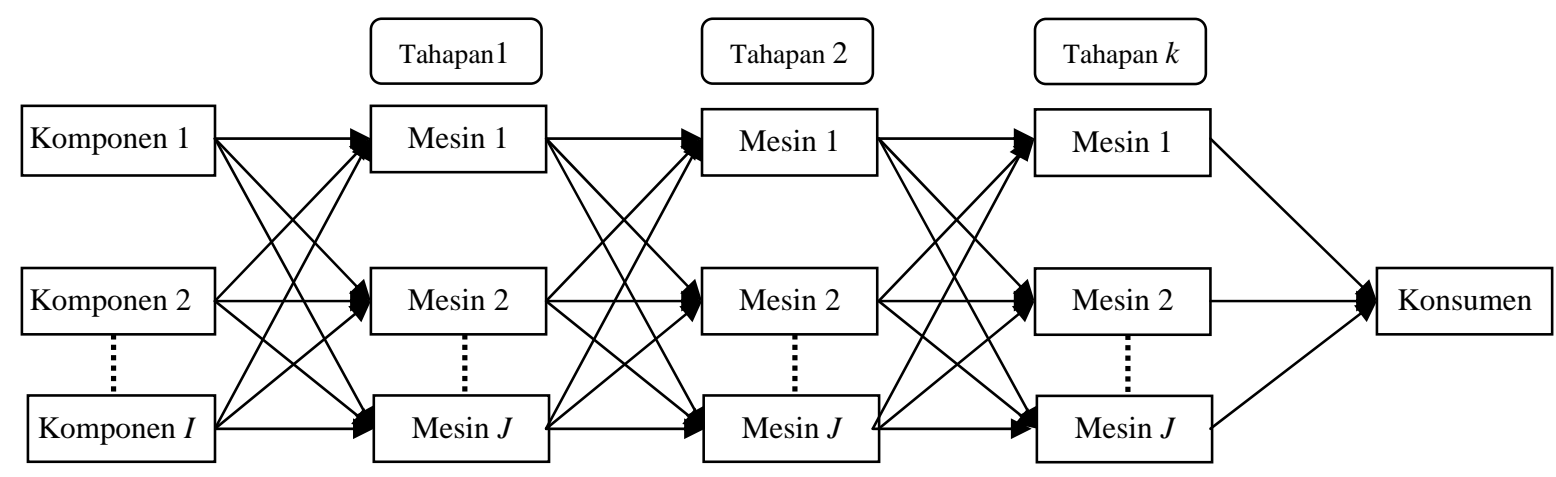

Gambar 2. Deskripsi Sistim Pemilihan Proses 
Jumlah komponen yang diproduksi harus dapat memenuhi pesanan konsumen sebesar $D$. Total waktu proses untuk memproduksi permintaan sebanyak $D$ harus lebih kecil atau sama dengan $d u e$ date yang telah ditentukan oleh konsumen. Jumlah komponen yang diproduksi pada setiap mesin tidak boleh melebihi kapasitas produksinya.

Proses yang akan terpilih adalah proses yang meminimumkan biaya manufaktur, biaya kerugian kualitas, dan biaya keterlambatan. Pada penelitian ini diasumsikan bahwa komponen akan diproses pada tahapan ke- $k$ setelah semua komponen selesai diproses pada tahapan sebelumnya $(k-1)$, setelah semua proses selesai komponen akan dikirim ke konsumen.

Sistim produksi yang dimodelkan dalam penelitian ini adalah proses produksi multi-stage dengan lebih dari satu mesin untuk memproduksi komponen. Biaya manufaktur tergantung pada alternatif proses yang terpilih. Biaya kerugian kualitas merupakan biaya yang ditanggung konsumen karena adanya variansi produk yang dihasilkan oleh proses produksi terpilih. Perumusan model optimasi pemilihan proses menggunakan pemrograman integer linier. Formulasi fungsi tujuan dalam model ini dinyatakan dengan persamaan berikut.

MinTC $=\sum_{i=1}^{I} \sum_{J=1}^{J} c_{i j k} x_{i j k} b_{i j k}+$
$\frac{A}{T^{2} R} x_{i j k} \sum_{i=1}^{I} \sum_{j=1}^{J}\left(\frac{\partial f}{\partial x_{i}}\right)\left(\frac{t_{i j k}}{3 c_{p}}\right)^{2} b_{i j k}+y L$

Model dalam penelitian ini mempunyai tiga pembatas, yaitu batasan kualitas, kapasitas mesin, dan permintaan.

\section{Batasan Kualitas}

Batasan kualitas diberikan agar akomodasi toleransi komponen $t_{i j}$ tidak melebihi batas toleransi rakitan $T_{R}$. Batasan tersebut dapat dirumuskan dalam persamaan berikut.

$\sum_{t=1}^{I} \sum_{j=1}^{J}\left(\left(\frac{\partial f}{\partial x_{i}}\right)^{2}\left(\frac{t_{i j k}}{C_{p}}\right)^{2} b_{i j}\right) \leq\left(\frac{T_{R}}{C_{p}}\right)^{2}$

\section{Batasan Kapasitas Mesin}

Setiap komponen ke- $i$ diproses pada mesin ke- $j$ pada tahapan ke- $k$ yang memiliki karakteristik waktu proses $w_{i j k}$ yang berbeda-beda. Penjumlahan waktu proses $w_{i j k}$ pada setiap mesin ke-j tidak dapat melebihi kapasitas yang dimiliki setiap mesin $\left(k_{j k}\right)$. Batasan kapasitas dapat dinyatakan seperti pada persamaan di bawah ini.

$$
\sum_{t=1}^{I} \sum_{j=1}^{J} x_{i j k} b_{i j k} \leq k_{j k}
$$

\section{Batasan Permintaan}

Agar perusahaan dapat memenuhi permintaan konsumen maka komponen $x_{i j k}$ yang diproduksi harus sama dengan permintaan sebanyak $D$.

$\sum_{j=1}^{J} x_{i j k} b_{i j k}=D \forall i, k$

\section{Batasan Indeks Biner}

Pembatas terakhir adalah indeks biner. Persamaan berikut menunjukkan bahwa setiap komponen ke-i dapat diproses dengan lebih dari satu mesin ke-j pada setiap tahap ke- $k$.

$$
\begin{aligned}
& \sum_{j=1}^{J} b_{i j k} \geq 1, \forall i, k \\
& b_{i j k} \in[0,1], \forall i, j, k
\end{aligned}
$$

Sedangkan persamaan di bawah ini menyatakan bahwa jumlah komponen yang diproduksi $x_{i j k}$ harus lebih besar dari nol.

$x_{i j k} \geq 0$ intejer

Batas waktu pengiriman pesanan merupakan due date yang ditentukan oleh konsumen. Perusahaan berusaha untuk menyelesaikan dan mengirim produk atau komponen sebelum due date. Apabila komponen atau produk dikirim setelah due date maka akan menimbulkan biaya keterlambatan.

$$
\begin{aligned}
& W_{k}=\max \left\{\sum_{i=1}^{I} x_{i j k} b_{i j k} w_{i j k}\right\}, \forall j, k \\
& W_{\text {max }}=\sum_{k=1}^{K} w_{k} \\
& w_{\text {max }}-w_{T}=\left\{\begin{array}{l}
\text { y,jika } w_{\text {max }}>w_{T} \\
0, j i k a w_{\text {max }} \leq w_{T}
\end{array}\right.
\end{aligned}
$$

\section{HASIL DAN PEMBAHASAN}

Contoh numerik digunakan untuk menunjukkan aplikasi model yang telah dikembangkan. Parameter untuk contoh numerik yang digunakan dalam makalah ini diperoleh dari penelitian Feng dkk. (2001) dengan melakukan penyesuaian sesuai kebutuhan. Produk rakitan tersusun atas tiga komponen yaitu $k_{1}$, $k_{2}$, dan $k_{3}$. Contoh produk rakitan yang tersusun dari 3 jenis komponen yang berbeda (Gambar 3 ).

Spesifikasi produk rakitan adalah $y=60,000 \pm$ $0,025 \mathrm{~mm}$. Setiap komponen $k_{1}, k_{2}$, dan $k_{3}$ berdistribusi 


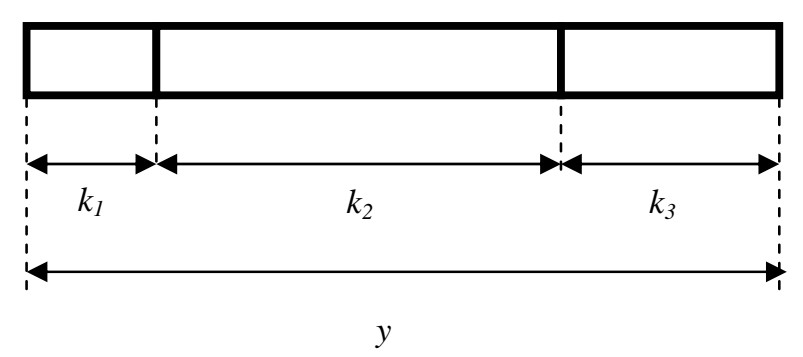

Sumber: Feng dkk. (2001)

Gambar 3. Produk Rakitan Beserta Komponen Penyusunnya.

normal dengan rataan $\mu_{1}=10,000 \mathrm{~mm}, \mu_{2}=20,000$ $\mathrm{mm}$ dan $\mu_{3}=30,000 \mathrm{~mm}$. Perusahaan mempunyai tiga proses dan dua tahapan proses yang digunakan untuk menghasilkan ketiga komponen tersebut. Ketiga proses produksi diwakili oleh tiga mesin yaitu $m_{1}, m_{2}$, dan $m_{3}$ yang dapat digunakan untuk memproses semua komponen.

Setiap mesin mempunyai karakteristik yang berbeda dalam hal biaya manufaktur, waktu proses, dan toleransi yang bisa dihasilkan. Tabel 1 menunjukkan data biaya manufaktur, waktu proses, dan toleransi yang dihasilkan untuk setiap komponen ke- $i$ yang diproses pada mesin ke-j. Pada contoh numerik ini diasumsikan semua mesin memiliki indeks kapabilitas proses sama yaitu $C_{p}=1,25$ untuk setiap komponen. Biaya keterlambatan diasumsikan sebesar Rp1000/menit.

Komponen 1 dapat diproduksi di mesin $m_{1}$ yang menghasilkan toleransi 0,008 mm. Biaya manufaktur di mesin 1 untuk komponen 1 sebesar Rp8000 dan waktu yang digunakan untuk memproses komponen tersebut sebesar 9 menit untuk setiap unitnya. Perusahaan menerima pesanan 100 unit produk rakitan. Kapasitas mesin 1, mesin 2, dan mesin 3 masing-masing sebesar 120 unit, 180 unit, dan 60 unit. Biaya kerugian kualitas diasumsikan sebesar 20000, sedangkan due date ditentukan 4 hari. Hasil optimisasi aplikasi model ditunjukkan pada Tabel 2.

Total biaya yang diperlukan untuk memproduksi pesanan adalah sebesar Rp5.390.970,00. Biaya
Tabel 2. Data Hasil Optimisasi

\begin{tabular}{crccccc}
\hline & \multicolumn{4}{c}{ Kuantitas Produksi (unit) } \\
\cline { 2 - 7 } Komponen & \multicolumn{3}{c}{ Tahap 1 } & \multicolumn{4}{c}{ Tahap 2 } \\
\cline { 2 - 7 } & $\mathbf{1}$ & $\mathbf{2}$ & $\mathbf{3}$ & $\mathbf{1}$ & $\mathbf{2}$ & $\mathbf{3}$ \\
\hline 1 & - & 25 & 75 & 100 & - & - \\
2 & 13 & 87 & - & - & 100 & - \\
3 & 100 & - & - & 16 & - & 84 \\
\hline
\end{tabular}

manufaktur sebesar Rp5.145.500,00 sedangkan biaya kerugian kualitas dan keterlambatan sebesar Rp9.470,35 dan Rp236.000,00. Dari hasil optimisasi diketahui bahwa pada tahap pertama komponen 1 diproses pada mesin 2 dan 3 dengan jumlah komponen yang diproduksi masing-masing sebesar 25 dan 75 unit. Komponen 2 diproduksi di mesin 1 dan mesin 2 dengan alokasi jumlah komponen masing-masing sebesar 13 dan 87 unit. Komponen 3 diproduksi di mesin 1 dengan jumlah komponen yang diproduksi sebesar 100 unit. Sedangkan pada tahapan kedua komponen 1 diproduksi pada mesin 1 dengan jumlah komponen sebesar 100 unit. Komponen 2 diproses pada mesin 1 dan mesin 2 dengan alokasi sebesar 13 dan 87 unit. Komponen 3 diproses pada mesin 1 dan mesin 3 dengan alokasi sebesar 16 dan 84 unit. Total waktu pengerjaan semua komponen atau produk adalah sebesar 2156 menit, sehingga terjadi keterlambatan sebesar 236 menit yang mengakibatkan biaya keterlambatan sebesar Rp236.000,00. Keterlambatan terjadi karena waktu proses pengerjaan setiap komponen lama, sehingga total waktu proses yang dihasilkan semakin besar.

\section{Analisis Sensitivitas}

Analisis sensitivitas dilakukan untuk mengetahui perubahan parameter model terhadap variabel keputusan dan fungsi tujuan. Parameter yang diubah adalah biaya kerugian kualitas $(A)$ dan nilai toleransi komponen. Skenario analisis sensitivitas dapat dilihat pada Tabel 3. Biaya kerugian kualitas yang digunakan adalah 10000, 20000, dan 40000. Pada tabel tersebut juga dapat dilihat besaran nilai toleransi proses untuk setiap komponen di setiap kasus. Sebagai contoh pada

Tabel 1. Data Biaya Manufaktur dan Waktu Proses untuk Setiap Komponen yang Diproses dengan Mesin yang Berbeda

\begin{tabular}{|c|c|c|c|c|c|c|c|c|c|}
\hline \multirow[b]{2}{*}{ Komponen } & \multicolumn{3}{|c|}{ Mesin 1} & \multicolumn{3}{|c|}{ Mesin 2} & \multicolumn{3}{|c|}{ Mesin 3} \\
\hline & $\begin{array}{l}\text { Toleransi } \\
\quad(\mathrm{mm})\end{array}$ & $\begin{array}{c}\text { Biaya } \\
\text { manufaktur } \\
(\mathrm{Rp})\end{array}$ & $\begin{array}{c}\text { Waktu } \\
\text { proses } \\
\text { (menit/ } \\
\text { unit) }\end{array}$ & $\begin{array}{c}\text { Toleransi } \\
\text { (mm) }\end{array}$ & $\begin{array}{c}\text { Biaya } \\
\text { manufaktur } \\
(\mathbf{R p})\end{array}$ & $\begin{array}{c}\text { Waktu } \\
\text { proses } \\
\text { (menit/ } \\
\text { unit) }\end{array}$ & $\begin{array}{l}\text { Toleransi } \\
\quad(\mathrm{mm})\end{array}$ & $\begin{array}{c}\text { Biaya } \\
\text { manufaktur } \\
(\mathbf{R p})\end{array}$ & $\begin{array}{c}\text { Waktu } \\
\text { proses } \\
\text { (menit/ } \\
\text { unit) }\end{array}$ \\
\hline 1 & 0,008 & 8000 & 9 & 0,005 & 11500 & 12 & 0,004 & 12000 & 13 \\
\hline 2 & 0,0075 & 9000 & 14 & 0,009 & 7000 & 8 & 0,003 & 13000 & 15 \\
\hline 3 & 0,01 & 6000 & 8 & 0,006 & 10000 & 11 & 0,006 & 9500 & 10 \\
\hline
\end{tabular}


kasus 1 toleransi proses komponen 1 pada setiap mesin di setiap tahapan masing-masing adalah 0,016 ; 0,$01 ; 0,008 ; 0,012 ; 0,01 ; 0,012$.

Terdapat lima kasus yang dibandingkan dalam analisis sensitivitas. Kasus pertama nilai toleransi semua komponen diubah menjadi dua kali lipat lebih besar dari pada nilai awal. Pada kasus tersebut diasumsikan biaya manufaktur dan waktu proses menjadi setengah kali dari nilai awalnya. Sedangkan kasus kedua, nilai toleransi komponen 1 dan komponen 2 diperbesar dua kali, dan tetap untuk komponen 3.

Setiap kasus akan dibandingkan dengan mengubah ketiga biaya kerugian kualitas. Hasil analisis sensitivitas dapat dilihat pada Tabel 4. Dari hasil analisis sensitivitas dapat diketahui bahwa perubahan nilai $A$ akan menyebabkan perubahan terhadap biaya kerugian kualitas. Biaya kerugian kualitas yang dihasilkan proporsional dengan perubahan nilai $A$. Perubahan nilai A juga akan menyebabkan perubahan biaya manufaktur pada kasus 3 dan 4 . Hal ini disebabkan karena nilai toleransi setiap proses pada komponen 2 lebih ketat dibandingkan dengan kasus-kasus yang lain. Biaya keterlambatan terjadi pada kasus 3 yaitu pada nilai A sebesar 10000 dan 40000.

\section{SIMPULAN}

Penelitian ini menghasilkan model optimisasi pemilihan proses untuk meminimumkan biaya manufaktur, biaya kerugian kualitas, dan biaya keterlambatan dengan memperhatikan batasanbatasan spesifikasi produk rakitan, waktu pengiriman, kapasitas produksi, dan pesanan konsumen. Analisis sensitivitas menunjukkan adanya perubahan terhadap biaya manufaktur, kerugian kualitas, dan biaya keterlambatan seiring perubahan biaya kerugian kualitas dan nilai toleransi. Penelitian selanjutnya dapat diarahkan pada pengembangan model untuk sistim produksi multi-tahap dengan mempertimbangkan masalah penjadwalan dengan alternatif proses dan routing yang berbeda untuk setiap komponen.

Tabel 3. Skenario Analisis Sensitivitas

\begin{tabular}{|c|c|c|c|c|c|c|c|c|c|c|c|c|c|c|c|c|c|c|}
\hline \multicolumn{4}{|c|}{$\mathrm{A}$} & & & & & & & & & & & & & & & \\
\hline Kasus 1 & 10000 & 20000 & 40000 & & & & & & & & & & & & & & & \\
\hline Kasus 2 & 10000 & 20000 & 40000 & & & & & & & & & & & & & & & \\
\hline Kasus 3 & 10000 & 20000 & 40000 & & & & & & & & & & & & & & & \\
\hline Kasus 4 & 10000 & 20000 & 40000 & & & & & & & & & & & & & & & \\
\hline \multirow[t]{4}{*}{ Kasus 5} & 10000 & 20000 & 40000 & & & & & & & & & & & & & & & \\
\hline & \multicolumn{6}{|c|}{ Komponen 1} & \multicolumn{6}{|c|}{ Komponen 2} & \multicolumn{6}{|c|}{ Komponen 3} \\
\hline & \multicolumn{2}{|c|}{ Mesin 1} & \multicolumn{2}{|c|}{ Mesin 2} & \multicolumn{2}{|c|}{ Mesin 3} & \multicolumn{2}{|c|}{ Mesin 1} & \multicolumn{2}{|c|}{ Mesin 2} & \multicolumn{2}{|c|}{ Mesin 3} & \multicolumn{2}{|c|}{ Mesin 1} & \multicolumn{2}{|c|}{ Mesin 2} & \multicolumn{2}{|c|}{ Mesin 3} \\
\hline & \multicolumn{6}{|c|}{ Tahap 1 Tahap 2} & TThon 1 & Tahap 2 & Tahap 1 & Tahap 2 & Tahap 1 & 1Tahap 2 & Tahap 1 & 1 Tahap & Tahap 1 & Tahap 2 & Tahap 1 & Tahap \\
\hline Kasus 1 & 0,016 & 0,01 & 0,008 & 0,012 & 0,01 & 0,012 & 0,015 & 0,018 & 0,006 & 0,012 & 0,014 & 0,008 & 0,02 & 0,01 & 0,012 & 0,016 & 0,018 & 0,01 \\
\hline Kasus 2 & 0,016 & 0,01 & 0,008 & 0,012 & 0,01 & 0,012 & 0,015 & 0,018 & 0,006 & 0,012 & 0,014 & 0,008 & 0,01 & 0,005 & 0,006 & 0,008 & 0,009 & 0,005 \\
\hline Kasus 3 & 0,016 & 0,01 & 0,008 & 0,012 & 0,01 & 0,012 & 0,0075 & 0,009 & 0,003 & 0,006 & 0,007 & 0,004 & 0,01 & 0,005 & 0,006 & 0,008 & 0,009 & 0,005 \\
\hline Kasus 4 & 0,016 & 0,01 & 0,008 & 0,012 & 0,01 & 0,012 & 0,0075 & 0,009 & 0,003 & 0,006 & 0,007 & 0,004 & 0,02 & 0,01 & 0,012 & 0,016 & 0,018 & 0,01 \\
\hline Kasus 5 & 0,008 & 0,005 & 0,004 & 0,006 & 0,005 & 0,006 & 0,015 & 0,018 & 0,006 & 0,012 & 0,014 & 0,008 & 0,02 & 0,01 & 0,012 & 0,016 & 0,018 & 0,01 \\
\hline
\end{tabular}

Tabel 4. Hasil Analisis Sensitivitas

\begin{tabular}{cccccc}
\hline Nilai A & Kasus & Biaya Manufaktur & $\begin{array}{c}\text { Biaya } \\
\text { Kerugian Kualitas }\end{array}$ & $\begin{array}{c}\text { Biaya } \\
\text { Keterlambatan }\end{array}$ & Proses Terpilih \\
\hline 10000 & & 2284000 & 11586,12 & 0 & $111-112-221-212-232-311-332$ \\
20000 & 1 & 2284000 & 23172,24 & 0 & $111-112-221-212-232-311-332$ \\
40000 & & 2284000 & 46344,47 & 0 & $111-112-221-212-232-311-332$ \\
10000 & & 3264500 & 22800,06 & 0 & $111-112-221-222-232-311-312-322$ \\
20000 & 2 & 3264500 & 19887,34 & 0 & $111-122-221-232-311-312-322$ \\
40000 & & 3248000 & 33431,45 & 0 & $111-121-122-221-222-232-311-331-312$ \\
10000 & & 4002000 & 6852,962 & 2000 & $111-112-221-231-222-232-331-312-322$ \\
20000 & \multirow{2}{*}{$*$} & 4380500 & 11909,75 & 0 & $111-112-221-222-232-321-331-312-322$ \\
40000 & & 4343500 & 28382,75 & 12000 & $111-112-221-212-222-331-312$ \\
10000 & & 3415000 & 7945,229 & 0 & $131-112-221-222-232-321-331-312-322$ \\
20000 & 4 & 3544500 & 19062,08 & 0 & $121-131-112-221-212-222-232-311-332$ \\
40000 & & 3254750 & 32039,82 & 0 & $111-112-122-221-212-232-311-332$ \\
10000 & & 2984000 & 9361,13 & 0 & $111-112-122-221-212-232-311-332$ \\
20000 & 5 & 2984000 & 18722,26 & 0 & $111-112-122-221-212-232-311-332$ \\
40000 & & 2984000 & 37444,52 & 0 & \\
\hline
\end{tabular}




\section{DAFTAR PUSTAKA}

Feng, C. X., Wang, J., dan Wang, J. S., 2000. An Optimixation Model for Concurrent Selection of Tolerances and Supplier. Computers and Industrial Engineering, 40, 15-33.

Hambali, A., Sapuan, S.M., Ismail, N., dan Nukman, Y., 2009. Composite Manufacturing Process Selection Using Analytical Hierarchy Process. International Journal of Mechanical and Materials Engineering, 4, 49-61.

Irianto, D., Makmoen, M., dan Taroepratjeka, H., 2004. Pengembangan Model Optimasi Biaya, Kualitas dan Delivery untuk Sistim Produksi Berbasis MTO-ETO. Jurnal TMI.

Irianto, D., dan Rahmat, D., 2008. A Model for Optimizing Process Selection for MTO Manufacturer with Appraisal Cost. Proceedings of The $9^{\text {th }}$ Asia Pasific Industrial Engineering and Management System Conference, 220-225.
Kumar, M. Siva, Islam, M. N., Lenin, N., Kumar, dan D. V., 2009. Optimum Tolerance Synthesis for Complex Assembly with Alternative Process Selection Using Bottom Curve Follower Approach. International Journal of Engineering, 3, 380-402.

Mustajib, M. I., 2010. Model Simultan Penentuan Toleransi Komponen Produk Rakitan dan Pabrik dalam Kolaborasi Manufaktur Make-to-Order. Jurnal Teknik Industri, 12 (2), 109-118.

Mustajib, M. I., dan Irianto, D., 2010. An Integrated Model for Process Selection and Quality Improvement in Multi-tahapan Process. Journal of Advanced Manufacturing Systems, 9 (1), 31-48.

Sivakumar, K., Balamurugan, C., dan Ramabalan, S., 2011. Simultaneous Optimal Selection of Design and Manufacturing Tolerances with Alternative Manufacturing Process Selection. Computer-Aided Design, 207-218.

Teeravaraprug, J., 2008. Outsourcing and Vendor Selection Model Based on Taguchi Loss Function. Songklanakarin Journal of Science and Technology, 30 (4), 523-530. 